\title{
A study for a fire spread mechanism of residential buildings with numerical modeling
}

\author{
C.-S. Ahn \& J.-Y. Kim \\ Fire Safety Research Division, \\ Korea Institute of Construction Technology, Korea
}

\begin{abstract}
This study is intended to present a computational standard model for combustibles, compartments and buildings. As performance based design is more popular, fire-intensity and fire-load have turned out to be very important factors for building design and can be predicted through some computational work. To predict and estimate the fire properties of a residential fire, we made some numerical models of combustibles, compartments and a residential building. In a bid to validate the estimate values, research was divided into three parts of step verifications. The first was for combustibles, the second was for compartments and the third was for the building. During each step, computational analysis results from numerical models were compared with real fire tests. For computational analysis, the Fire Dynamics Simulator was used with Large Eddy Simulation model for turbulence. Consequently, fire-intensity was well predicted and flash-over of rooms were successfully estimated.

Keywords: combustible, compartment, real scale fire test, numerical analysis, fluid dynamics simulator.
\end{abstract}

\section{Introduction}

In line with increasingly popularized performance based design (PBD), the need of numerical analysis of building fires used to collect the data required for building design has been on the rise. Predicting fire growth and smoke spread pattern enables us to allow safe evacuation and analyze the caloric value. Radiant heat enables us to predict the potential damage to the structural member by fire heat. In addition, calculating the amount of toxic gas enables us to predict the level of exposure to toxic gas the people inside, to thereby providing data needed 
in selecting safe interior finish material. And it would be possible to provide the useful data for determining the location and capacity of smoke control devices and life-safety systems if we could analyze the air flow pattern within the fire space.

It is true that at present, the method to predict fire phenomena through numerical analysis is not as precise and convenient as real fire test. However, more effective techniques are being suggested by many researchers and the numerical analysis is increasingly gaining reliability through various case studies on the real fire tests and comparative verification. As a study of the numerical analysis on the flame of laboratory level, Hamins et al. [1] analyzed the combustion phenomena of a wax candle, and the study result on the mediumscale pool fire was verified by Wen et al. [2]. Recently, heat flux and flame height of the blaze predicted in SBI (single burning item) were researched by Jianping et al. [3]. As a study on the larger fire phenomenon, Hurley [4] conducted research in numerical analysis models to predict post-flashover of compartment fire, and Pope and Bailey [5] carried out quantitative comparison through prediction of post-flashover by fire curve and numerical analysis towards the fire occurred in the compartment. These days, improvement of computing performance leads to studies on the large fire phenomenon, such as prediction of effusive flame from a building balcony [6] and numerical analysis on the building collapse of World Trade Center 5 [7] and, in particular, research to verify the numerical analysis on the large space like-tunnel and atrium [8-10] are under study. In addition, researches deducing advanced numerical analysis results through improved modelling [11-13] and research predicting the performance of active systems, like smoke control facilities and sprinkler installation, based on the numerical analysis [14-16] are actively being conducted.

Numerical analysis of fire space in this study was carried out over three stages in a bid to enhance the reliability. First, numerical analysis was conducted after modeling a number of combustibles. Second, numerical analysis was conducted for the case when a multiple number of combustibles were burning together after modeling the compartment. Lastly, numerical analysis was conducted for the case when a multiple number of compartments were caught on a fire after modeling an entire floor of a residential building. The results of the numerical analysis obtained from each stage were verified by comparing with the heat release rate (HRR) or the temperature.

Fire Dynamic Simulator (FDS) used for analysis was the common program developed by the BFRL group of NIST in the USA [17], which is the popular fire analysis software of $3 \mathrm{D}$ field models. It has been commonly used for analyzing the air flow pattern induced by fire, heat transfer inside the fluid and solid and combustion of the flammables. 


\section{Numerical analysis of unit combustibles}

\subsection{Modeling of the combustibles}

Among the furniture and household care products, 10 kinds were selected considering fire load and material characteristics. The appearance was simplified through modeling and physical properties were defined as described in Table 1.

Table 1: $\quad$ Modeling of representative inflammables.

\begin{tabular}{|c|c|c|}
\hline Combustible & Material & Weight \\
\hline Cloth & Fiber & $5 \mathrm{~kg}$ \\
\hline Table & Wood & $30 \mathrm{~kg}$ \\
\hline Television & Synthetic resin & $30 \mathrm{~kg}$ \\
\hline Couch(1) & Leather, Wood & $18 \mathrm{~kg}$ \\
\hline Couch(3) & Leather, Wood & $35 \mathrm{~kg}$ \\
\hline Chair & Fiber, synthetic resin & $8 \mathrm{~kg}$ \\
\hline Wardrobe & Wood & $43 \mathrm{~kg}$ \\
\hline Bed & Fiber, Wood & $34 \mathrm{~kg}$ \\
\hline Desk & Wood & $33 \mathrm{~kg}$ \\
\hline Bookshelf & Wood & $31 \mathrm{~kg}$ \\
\hline Sink set & Wood & $55 \mathrm{~kg}$ \\
\hline Refrigerator & synthetic resin & $60 \mathrm{~kg}$ \\
\hline
\end{tabular}

\subsection{Modeling of combustion room}

Modeling of combustion room was conducted to provide the same numerical analysis condition as a full-scale fire test. For the fire test, Room Corner Tester, according to the international standard ISO-9705, was used. The modeling of combustion room was carried out in a $36 \times 24 \times 24$ grid (Figure 1), the same size as Room Corner Tester. The combustibles were placed at the center of combustion room and the condition of air inflow and exhaust outflow were arranged according to ISO 9705 requirements.

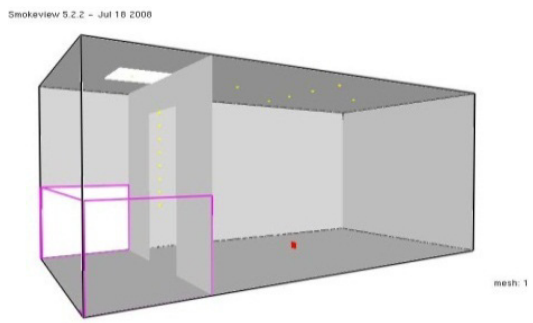

Figure 1: Numerical analysis model of combustion room. 


\subsection{Heat release rate $[\mathrm{kW}]$}

The heat release rate of the combustibles is dependent on components of major materials and the area exposed to the air. Figure 2 shows the quantitative comparison of heat release rates between the full-scale combustion test (labelled Exp.) and numerical analysis (labelled FDS).

Comparing a full-scale combustion test with the numerical analysis result from the qualitative aspect, heat release rate of the combustibles varied depending on material, as indicated in Figure 2. When it comes to the combustibles comprising the fiber and synthetic resin, the pattern of qualitative heat release rate was monitored similarly but showed differences in wooden material. While a full-scale combustion test showed low heat release rate over extended time, numerical analysis showed a high rate during a short time. Such a pattern was attributable to the characteristic of wooden material that inflammable gas discharged by pyrolysis causes flaming combustion at an early stage but it begins turning to smoldering combustion as inflammable gas is reduced and the char is generated inside the material. FDS5 can simulate such combustion process, but there might be a limit in simulating such a complex combustion process accurately. When comparing the highest heat release rate, the gap was about 20 percent in predicting the heat release rate and 10 percent in terms of time.

\section{Numerical analysis of the compartment}

\subsection{Modeling of the compartment}

Modeling of the compartment was carried out for four different cases as it is for a full-scale test, and it is divided into the living room $(4.8 \times 2.4 \times 2.4 \mathrm{~m})$, large room $(4.3 \times 3.2 \times 2.4 \mathrm{~m})$, small room $(2.4 \times 2.4 \times 2.4 \mathrm{~m})$ and kitchen $(2.4 \times 2.1 \times 2.4 \mathrm{~m})$.

\subsection{Flame spread by compartment}

The fire source of each compartment was placed at the bottom of the furniture inside. Table 2 shows the peak time of heat release rate.

As a result of numerical analysis, it took 4 minutes 48 seconds in the living room, 4 minutes 5 seconds in the large room, 4 minutes 10 seconds in the small room and 5 minutes 48 seconds in the kitchen to reach the peak time of heat release rate. But, in the case of a full-scale test, it took 7 minutes 21 seconds in the living room, 6 minutes 37 seconds in the large room, 5 minutes 43 seconds in the small room and 18 minutes 57 seconds in the kitchen. When comparing the result quantitatively, numerical analysis predicts the peak time 12 percent earlier.

\subsection{Heat release rate $[\mathrm{kW}]$ in the compartment}

From a quantitative standpoint, a full-scale test indicated the highest heat release rate as shown in Figure 4, 5930.1kW in the living room, $7433.3 \mathrm{~kW}$ in the large room, $5971.5 \mathrm{~kW}$ in the small room and $5131 \mathrm{~kW}$ in the kitchen while numerical 

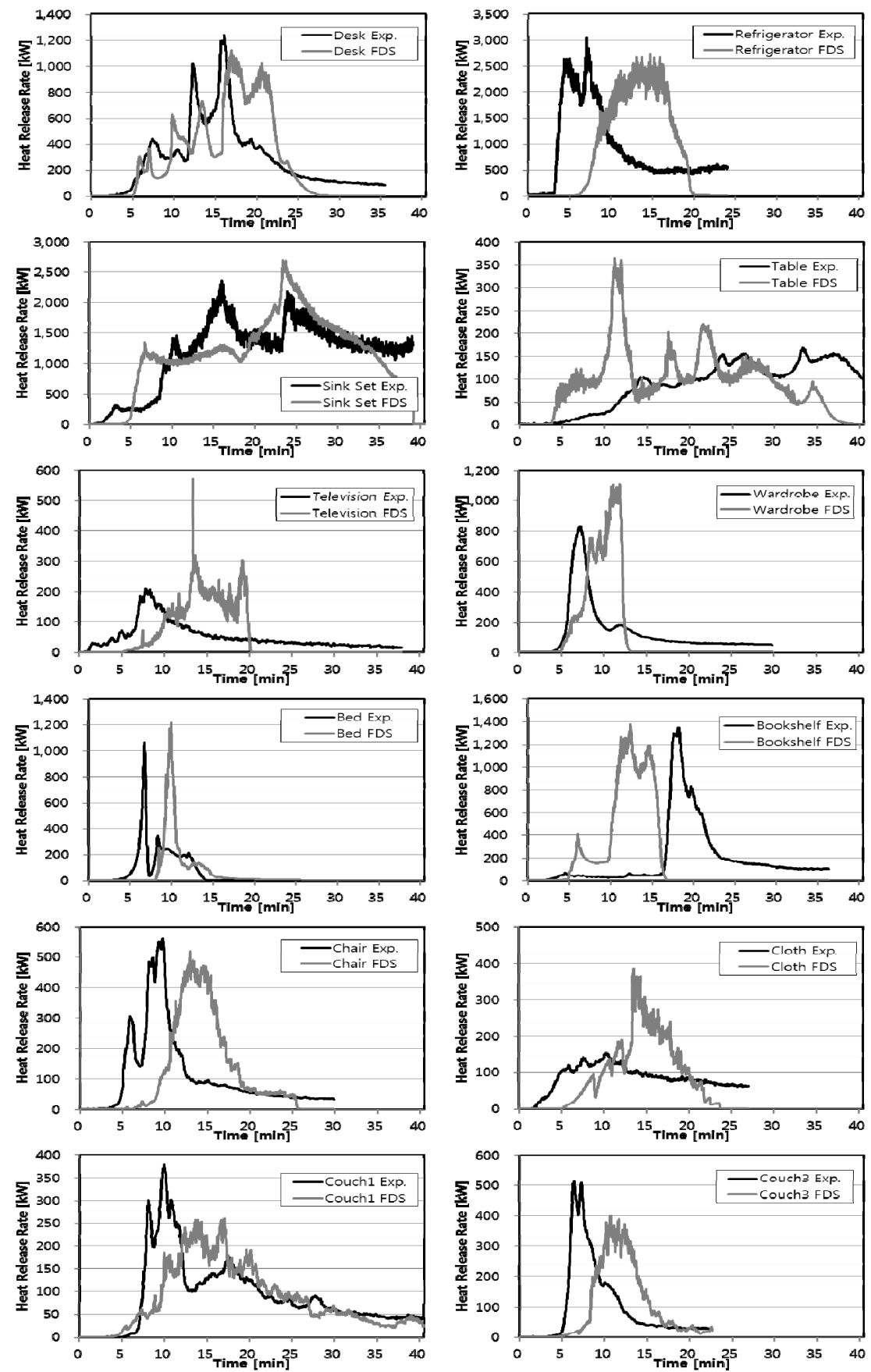

Figure 2: Comparison of heat release rates between combustion test by type of combustibles and numerical analysis. 

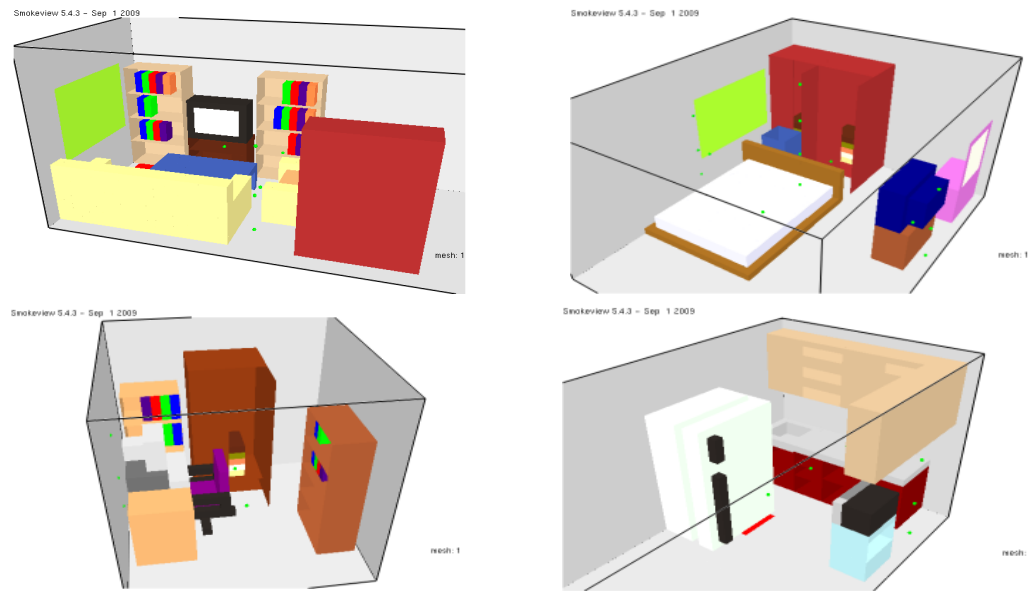

Figure 3: Completed modeling of numerical analysis in the compartment.

Table 2: $\quad$ Comparison of the peak time by compartment.

\begin{tabular}{|c|c|c|}
\hline Compartment & Real Fire Test [sec] & Numerical Analysis [sec] \\
\hline Living Room & 441 & 288 \\
\hline Large Room & 397 & 245 \\
\hline Small Room & 343 & 250 \\
\hline Kitchen & 1137 & 348 \\
\hline
\end{tabular}
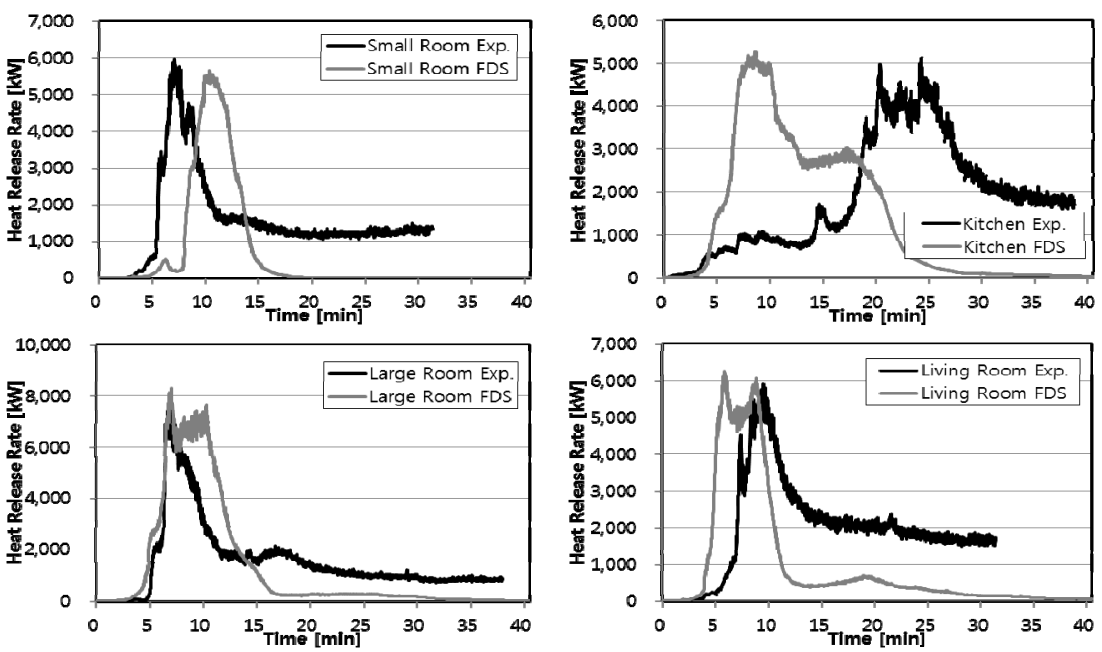

Figure 4: Comparison of heat release rates between combustion test by type of compartments and numerical analysis. 
analysis indicated $6341.0 \mathrm{~kW}$ in the living room, $8302.1 \mathrm{~kW}$ in the large room, $5590.9 \mathrm{~kW}$ in the small room and $6201.3 \mathrm{~kW}$ in the kitchen. Viewing the above results, numerical analysis overestimated the full-scale test by 11 percent of standard deviation.

\subsection{Variation of temperature by compartment}

Variation of temperature in the compartment showed a similar pattern as the variation of heat release rate. As seen in Figure 5, the highest temperature during a full-scale test was $948^{\circ} \mathrm{C}$ in the living room, $1,066^{\circ} \mathrm{C}$ in the large room, $866^{\circ} \mathrm{C}$ in the small room and $962^{\circ} \mathrm{C}$ in the kitchen, indicating the temperature was $900^{\circ} \mathrm{C}$ or above in all compartments. In the case of the numerical analysis, the temperatures were $788^{\circ} \mathrm{C}$ in the living room, $764^{\circ} \mathrm{C}$ in the large room, $935^{\circ} \mathrm{C}$ in the small room and $955^{\circ} \mathrm{C}$ in the kitchen, which underestimated by 15 percent of standard deviation.
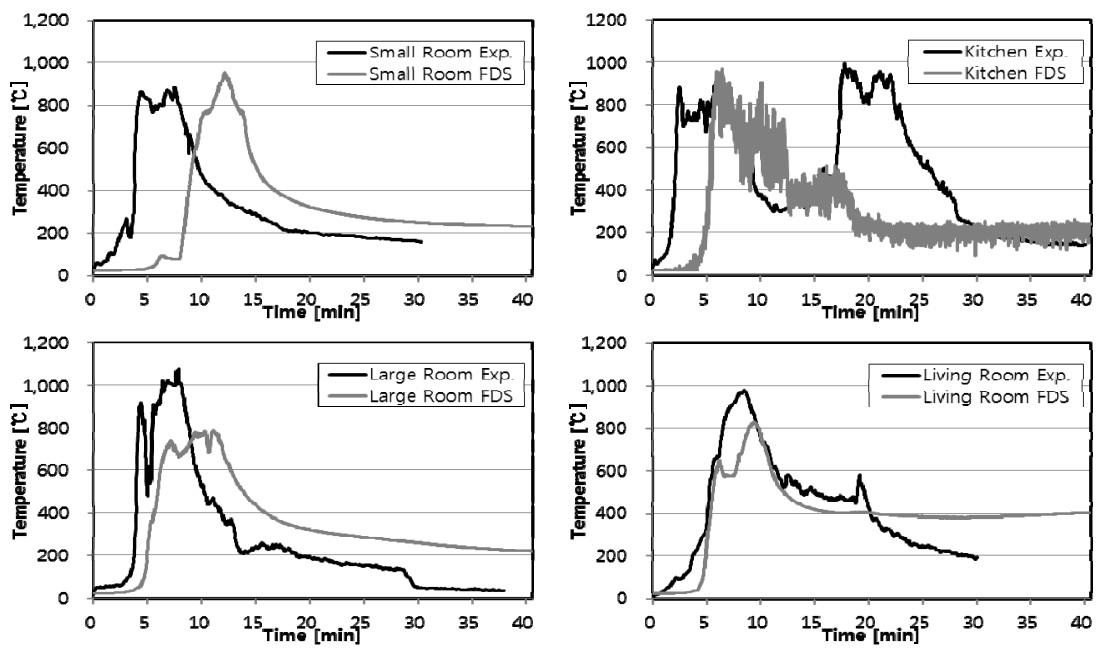

Figure 5: Comparison of temperature of $1.5 \mathrm{~m}$ height between combustion test by type of compartments and numerical analysis.

\section{Numerical analysis of residential building}

\subsection{Fire numerical analysis modeling of residential building}

The numerical analysis model comprised of four floors the same as the real building. The third floor $\left(80 \mathrm{~m}^{2}\right)$ where fire occurred comprised of a lobby, living room, kitchen, larger room, small room, study room, bathroom, entrance and balcony (Figure 6). Temperature was measured at the same location as a fullscale fire test and the fire source was set in the kitchen. 


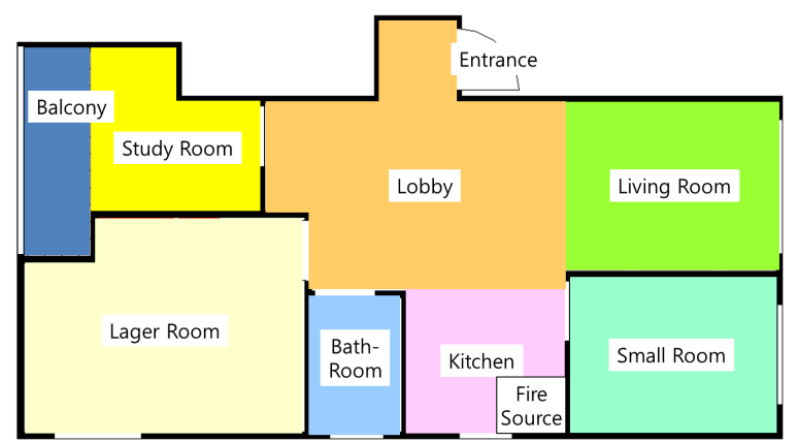

Figure 6: View of fire test and ignition at the fire source in modelling.

The grid in the calculation territory used was $136 \times 104 \times 112$ uniform rectangular grid. Staircase was linked into the indoor space and entire building structure could be viewed through the side section and front section. Figure 7 shows each floor section of the building and also the layout of inflammables in analysis territory on the $3^{\text {rd }}$ floor.
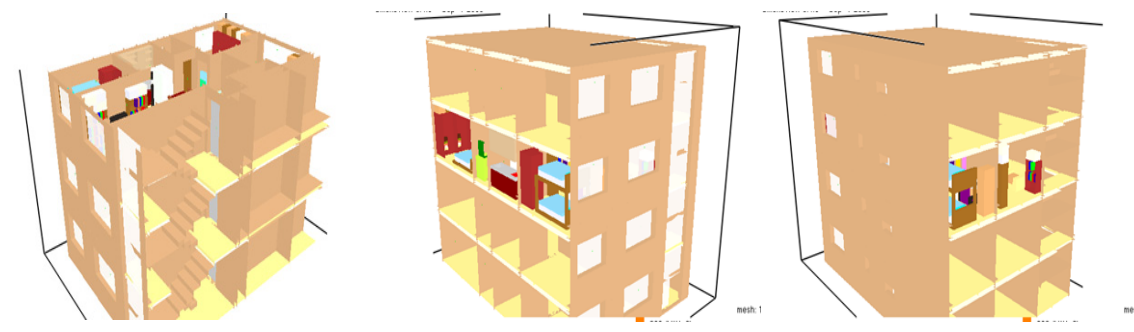

Figure 7: Modeling section of the residential building.

Numerical analysis was carried out over 11 hours in a way of connecting 64 CPUs in a row and to reproduce the actual fire time of 28 minutes (1680 seconds).

\subsection{Fire scenario}

To help the fire develop to the flash-over fire in short time in a full-scale fire test, it is designed with the kitchen where the initial heat release rate is larger. According to the scenario, $800 \mathrm{cc}$ soybean oil heated in a $\varnothing 0.35 \mathrm{~m}$ frying pan ignites. In numerical analysis, a similar fire source was set at the same location. Figure 8 shows the soybean oil igniting and the ignition by numerical analysis modeling. 


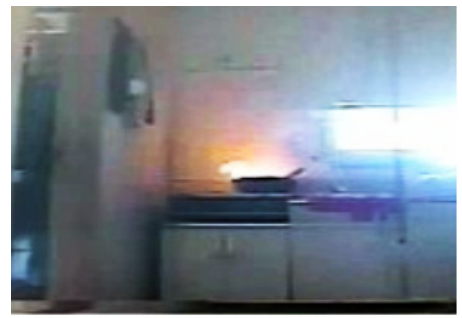

Real fire test

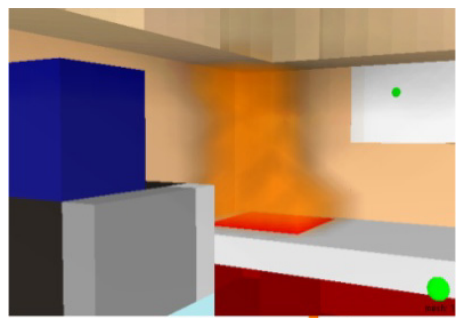

Numerical analysis

Figure 8: $\quad$ Soybean oil igniting.

\subsection{Major changes depending on time variation}

Fire was grown and developed qualitatively through the same flame spread process as the full-scale fire. A minute after natural ignition, smoke began going out through the balcony and living room window; and in six minutes, when the entrance door was opened, the fire inside rapidly grew and the front windows in the living room were broken; and in 24 minutes, the windows in the balcony were broken by the flame when developed to the small room and balcony. Figure 9 shows the comparison between the scenarios.

Table 3: Comparison between the fire test and numerical analysis of the residential building fire.

\begin{tabular}{|c|c|}
\hline Time & Real Fire Test \\
\hline $0 \mathrm{~min}$ & Ignition start \\
\hline $1 \mathrm{~min}$ & Emission of smoke \\
\hline $6 \mathrm{~min}$ & Entrance door open \\
\hline $11 \mathrm{~min}$ & $\begin{array}{c}\text { Break of living and small } \\
\text { room window }\end{array}$ \\
\hline $16 \mathrm{~min}$ & Crack of balcony window \\
\hline $20 \mathrm{~min}$ & Break of balcony window \\
\hline $28 \mathrm{~min}$ & Test terminate \\
\hline
\end{tabular}

\begin{tabular}{|c|c|}
\hline Numerical Analysis & Time \\
\hline Ignition start & $0 \mathrm{~min}$ \\
\hline Emission of smoke & $1 \mathrm{~min}$ \\
\hline Entrance door open & $6 \mathrm{~min}$ \\
\hline $\begin{array}{c}\text { Break of living and small } \\
\text { room window }\end{array}$ & $12 \mathrm{~min}$ \\
\hline $\begin{array}{c}\text { Crack of balcony window } \\
\text { Break of balcony window }\end{array}$ & $24 \mathrm{~min}$ \\
\hline Analysis terminate & $28 \mathrm{~min}$ \\
\hline
\end{tabular}

\subsection{Temperature variation by compartment}

Kitchen is the place where the fire source is located and spreads out the first. In fire test, floor temperature in kitchen rapidly rose which developed the flash-over in 13 minutes, while in numerical analysis, floor temperature in kitchen rose to $500^{\circ} \mathrm{C}$ or above in 10 minutes which developed the flash-over.

Living room is an open space without any physical partition against the lobby or kitchen, and thus the smoke and flame generated from the fire source can 


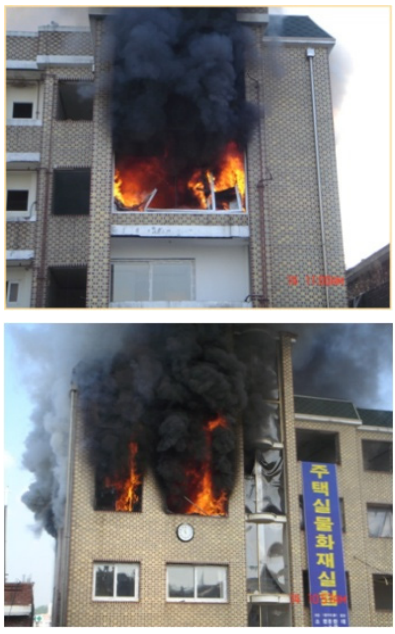

Real fire test

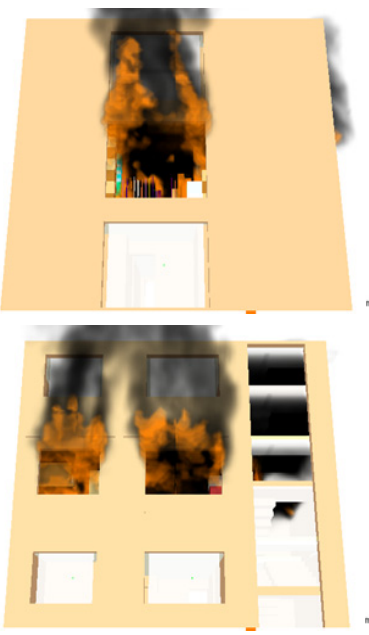

Numerical analysis

Figure 9: $\quad$ Modeling of living space by floor.
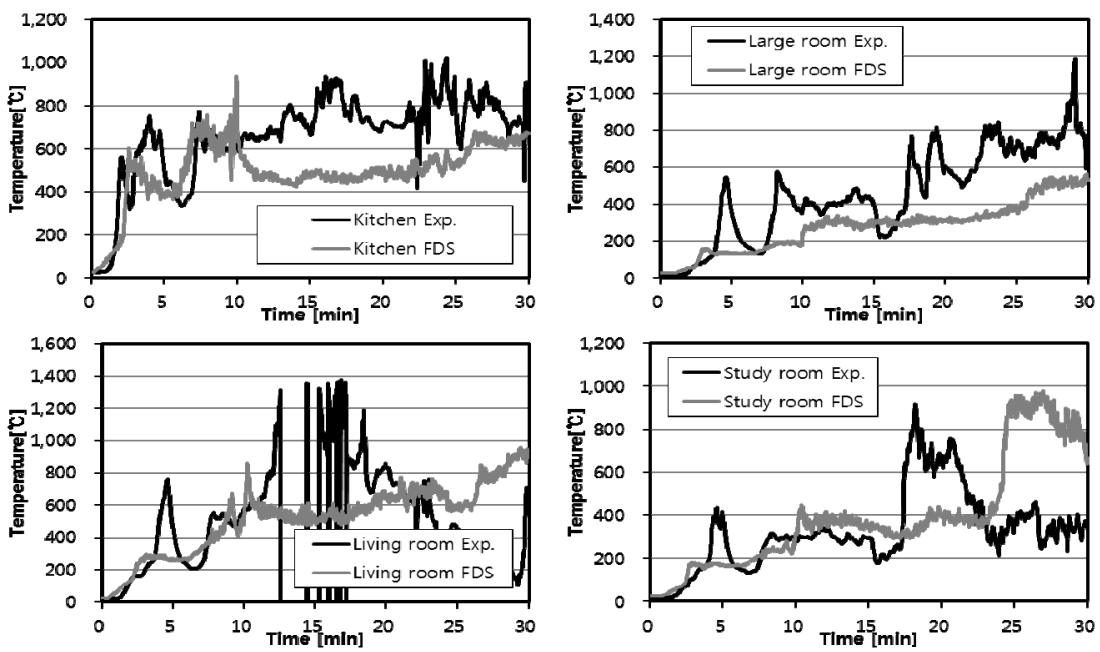

Figure 10: Comparison of temperature distribution by height at the center of the large room.

rapidly spread to the living room by ceiling jet-flow. When comparing the flashover which occurred in the living room, it is monitored in 12 minutes in fire test, while it appeared in 10 minutes according to the numerical analysis, indicating an insignificant time gap with the kitchen.

A small room is just next to the kitchen but it is partitioned by fire-rated wall and contains many inflammables in a small space. In fire test, flash-over in the 
small room occurred in 17 minutes, but according to the numerical analysis, no flash-over occurred, which appeared to be attributable to the windows in the small room which remained undamaged.

In fire test, flash-over time was relatively late compared to the lobby or the living room (about 18 minutes) but was earlier than the large room (22 minutes). According to numerical analysis, flash-over occurred in 24 minutes.

When it comes to the large room, it is separated from the kitchen (where the fire source is located) and the entrance by fire-rated wall and the area of openings is small for the area of the room. Because of such reasons, flash-over occurred in this room last (22 minutes 30 seconds). According to the numerical analysis, flash-over was restrained and did not occur.

Table 4: Comparison of flash-over between the fire test and numerical analysis of the fire in residential building.

\begin{tabular}{|c|c||c|c|}
\hline Time & Real Fire Test F/O & Numerical analysis F/O & Time \\
\hline $13 \mathrm{~min} 30 \mathrm{sec}$ & Kitchen & Kitchen & $10 \mathrm{~min} 00 \mathrm{sec}$ \\
\hline $17 \mathrm{~min} 00 \mathrm{sec}$ & Lobby & Living room & $10 \mathrm{~min} 30 \mathrm{sec}$ \\
\hline $12 \mathrm{~min} 15 \mathrm{sec}$ & Living room & Lobby & $11 \mathrm{~min} 30 \mathrm{sec}$ \\
\hline $17 \mathrm{~min} 15 \mathrm{sec}$ & Small room & Small room & - \\
\hline $18 \mathrm{~min} 15 \mathrm{sec}$ & Study room & Study room & $24 \mathrm{~min} 30 \mathrm{sec}$ \\
\hline $22 \mathrm{~min} 30 \mathrm{sec}$ & Large room & Large room & - \\
\hline
\end{tabular}

\section{Conclusion}

A minute after natural ignition, dark smoke began coming out through the balcony at the side and the living room; and in six minutes, when the fire door was opened, the fire rapidly grew; and in 12 minutes, front windows were broken; and in 24 minutes, windows in rear balcony were broken by the frame spread to the study room and rear balcony.

Viewing such results, fire models of residential buildings could predict qualitatively the flame spread and flash-over in a full-scale fire test. As a result of quantitative comparison, temperature prediction was underestimated by 20 percent of standard deviation compared to fire test and the time prediction was done late by 15 percent of standard deviation.

\section{References}

[1] A. Hamins, M. Bundy et al., "Characterization of Candle Flames", Journal of Fire Protection Engineering, Vol.15, 2005.

[2] J.X. Wen, K. Kang, T. Donchev, J.M. Karwatzki, "Validation of FDS for the prediction of medium-scale pool fires", Fire Safety Journal, Vol.42, pp.127, 2007. 
[3] Jianping Z., Michael D., Matthieu C., "Assessment of Fire Dynamic Simulator for Heat Flux and Flame Heights Predictions from Fires in SBI Tests", Fire Technology, Vol.46, pp.291, 2010.

[4] M.J. Hurley, "Evaluation of Models of Fully Developed Post-flashover Compartment Fires", Journal of Fire Protection Engineering, Vol.15, 2005.

[5] N.D. Pope, C.G. Bailey, "Quantitative comparison of FDS and parametric fire curves with post-flashover compartment fire test data", Fire Safety Journal, Vol.41, pp.99, 2006.

[6] R. Harrison, M. Spearpoint, "A Simple Approximation to Predict the Transition from a Balcony Spill Plume to an Axisymmetric Plume", Journal of Fire Protection Engineering, Vol.20, 2010.

[7] K.J. LaMalva, J.R. Barnett, "Failure Analysis of the World Trade Center 5 Building", Journal of Fire Protection Engineering, Vol.19, 2009.

[8] M.K. Cheong et al., "Calibrating an FDS Simulation of Goods-vehicle Fire Growth in a Tunnel Using the Runehamar Experiment", Journal of Fire Protection Engineering, Vol.19, 2009.

[9] G. Rein, J.L. Torero, W. Jahn et al., "Round-robin study of a priori modelling predictions of the Dalmanock Fire Test One", Fire Safety Journal, Vol.44, pp.590, 2009.

[10] S. Kerber, J.A. Milke, "Using FDS to Simulate Smoke Layer Interface Height in a Simple Atrium”, Fire Technology, Vol.43, pp.45, 2007.

[11] S.M. Olenick, D.J. Carpenter, "An Updated International Survey of Computer Models for Fire and Smoke", Journal of Fire Protection Engineering, Vol.13, 2003.

[12] G. Rein, A. Bar-ilan, C. Fernandez-pello, "A Comparison of Three Models for the Simulation of Accidental Fires", Journal of Fire Protection Engineering, Vol.16, pp.183, 2006.

[13] M. Hjohlman, P. Andersson et al., "Flame Spread Modelling of Complex Textile Materials", Fire Technology, Vol.47, pp.85, 2009.

[14] B.P. Husted et al., "Influence of Draft Curtain in Sprinkler ActivationComparison of Three Different Models", Journal of Fire Protection Engineering, Vol.18, 2008.

[15] A. Kashef, N. Benichou, "Investigation of the Performance of Emergency Ventilation Strategies in the Event of Fires in a Road Tunnel-A Case Study", Journal of Fire Protection Engineering, Vol.18, 2008.

[16] J. Trelles, J.R. Mawhinney, "CFD Investigation of Large Scale Pallet Stack Fire in tunnels Protected by Water Mist Systems", Journal of Fire Protection Engineering, Vol.20, 2010.

[17] NIST, FDS (Fire Dynamics Simulator) User's Guide, 2010. 